\title{
Unintentional pediatric injuries in São Paulo. How often is it severe? ${ }^{1}$
}

Simone de Campos Vieira Abib', Alessandra Mara Françóia", Renata Waksman"', Maria Inês Dolci'"v, Hélio Penna Guimarães`, Frederico Moreirav, Marcus Vinícius BoarettoCezillo', Adenauer Marinho Góes Júnior ${ }^{\mathrm{VI}}$

\begin{abstract}
'Associate Professor, Department of Surgery, Universidade Federal de São Paulo (UNIFESP). President, Organização Não Governamental (ONG) Criança Segura, Brazil. Conception and design of the study, analysis and acquisition of data, approval the final version to be published.

"Ms, National Coordinator, ONG Criança Segura, São Paulo-SP, Brazil. Design of the study, analysis and acquisition of data. I'PhD, Department of Childhood Safety, Sociedade Brasileira de Pediatria, São Paulo-SP, Brazil. Design of the study, critical revision, approval the final version to be published.

IVAssociação Brasileira de Defesa do Consumidor (PROTESTE), São Paulo-SP, Brazil. Design of the study, critical revision, approval the final version to be published.

${ }^{\vee}$ PhD, Teaching and Simulation Center of HCor (CETES-HCor), São Paulo-SP, Brazil. Statistical analysis.

V'Associate Professor, Department of Surgery, UNIFESP, and Universidade Federal do Pará (UFPA), Brazil. Critical revision, approval the final version to be published.
\end{abstract}

\section{Abstract}

Purpose: To evaluate severity and built a pilot of a national databank about pediatric trauma and to determine its severity.

Methods: Prospective study of unintentional pediatric trauma in five hospitals in the city of São Paulo, Brazil.

Results: 916 patients in 4 months. $61.5 \%$ of traumatized children were male, average 6.5 years. $48.4 \%$ were falls. Most families had an average monthly income less than three minimum wages. $42 \%$ of accidents occurred at home. $18.9 \%$ of children were alone. $59,8 \%$ of parents thought it could be prevented. $26.5 \%$ of children had previous accidents. GCS was severe: 5 patients, moderate: 8 patients. 21 patients were intubated (2.4\%), RTS $<7$ in $10.2 \%$, PTS $<8$ in $3.6 \% .8 .5 \%$ patients were considered severe, which was related to falls $(p=0.001)$; sports $(p=0.045)$; pedestrian $(p=0.006)$; child education $(p=0.015)$ and cared by male $(p=0.007)$.

Conclusions: Severity occurred in $8.5 \%$ and was associated to falls, sports, traffic, child education, and cared by male. Simple preventive measures could have prevented most of the accidents. The tested tool for details was successful and can be used throughout the country. Key words: Wounds and Injuries. Accident Prevention. Pediatrics. 


\section{Introduction}

According to the World Health Organization $(\mathrm{WHO})^{1}$, about 6 million people die of trauma worldwide each year. It is estimated that of these, 830.000 deaths and 50 million sequelae are aged from 0 to 14 years and over $90 \%$ of deaths occur in developing countries.

In the last 40 years, the organization of care for polytrauma had unquestionable impact on reducing morbimortality, but unfortunately the same was not true for the traumatized child, which can be treated in various types of structures ${ }^{1}$ and with or without pediatric specialists.

Added to those, there is the fact that pediatric specialists committed to trauma are few and that trauma experts feel insecure when looking after children, both in the prehospital and intra-hospital phases.

The American College of Emergency Physicians and the American Academy of Pediatrics reported that only $6 \%$ of American emergencies have all the equipment needed in pediatric care, besides the insecurity of professionals who provide care. Even in the US, where there are pediatric trauma centers, a study showed that children and adolescents up to 15 years of age are 60 minutes away from one of these centers and that 17.4 million children in this age group have no access to them, especially in rural areas. These facts lead to the need of restructuring the system for children, to optimize the treatment of children within the planning trauma system ${ }^{2,3}$. This is also true for disaster scenarios, where the best-trained professionals feel frustrated treating children, there is lack of pediatric equipment in a war scenario, where in addition to the challenges of the care of children, there is the fact that they are often separated from their families ${ }^{4}$.

In Brazil, Abib et al. ${ }^{4}$ evaluated approximately 13.000 children and adolescents treated at the pre-hospital in the city of São Paulo and, although this number is not small, it constituted only $4 \%$ of all dispaches during the study period.A dispatch system of advanced support for children, validated with other indices of international gravitywas proposed, which can optimize the use of this scarce and expensive resource in approximately $30 \%$. In Brazil, the general surgeon is the first to care for children (46\%) and the follow-up of the traumatized child is made by the general surgeon and the pediatric surgeon. Only $60 \%$ feel safe to operate a traumatized child and $66 \%$ feel emotionally unprepared or do not have access to the specific material for the care of children. $50 \%$ of participants cared for 1-6 traumatized children in the last month of the survey, $40 \% 15-20$ and $10 \%$ more than 20 children traumatized. In $40 \%$ of the participant's workplaces, the materialfor pediatric life support was in emergency surgery room and $10 \%$ in the pediatric emergency room.

Official data from Brazil $^{5}$ show that the main cause of mortality among children and young people up to 19 years are external causes (21.000-22.000 deaths/year), with dramatic increase in cases related to violence and motorcycles. Although there has been an evident increase in violence in the country, the main causes of death (79\%) are accidents and not violence from 0 to 14 years of age.The same applies to admissions: $89 \%$ of them are due to accidents and only $4 \%$ to violence.

The Non-Governmental Organization (NGO) Safe Kids Brazil stratifies the official data on age groups in terms of mortality and hospitalization annually. Traffic accidents (40\%) stand out; drowning (25\%), suffocation (15\%), burns (6\%), falls (4\%), intoxications (2\%) as causes of death. Stratified by age group, $0-1$ year suffocation is the leading cause of mortality; in the age groups 1-4, 5-9 and 10-14 stand out traffic accidents and drownings, followed by falls. When analyzing the hospitalization data, 
falls are the leading cause of hospitalization (48\%), followed by burns (16\%), traffic accidents $(12 \%)$, poisoning $(4 \%)$, suffocation $(1 \%)^{6}$. Safe Kids Brazil has accomplished to change laws refering to child safety in Brazil and is reference in the country for Child Safety, having reached a $30 \%$ decrease in childhood trauma mortality in 15 years of existence.

A study of medical pre-hospital system in Brazil showed that $51.5 \%$ of physicians feel unprepared to meet traumatized children; $34.9 \%$ have difficulties in pediatric semiology and $62.4 \%$ have difficulty pediatric advanced life support procedures ${ }^{7}$.

From the data, rather than having to train many professionals and organize capable and effective trauma care systems, the best to do is to invest in prevention.

Although the Ministry of Health official data on mortality and hospitalizations are quite reliable, little is known about trauma severity in pediatric patients. So a tool was created in order to evaluate severity and to be used as a national database to guide pediatric prevention and care system and that has been tested in a pilot study in five hospitals in the city of São Paulo.

\section{- Methods}

This study was approved by the Research Ethics Committee, UNIFESP-EPM (process number 78508/12). Parents or guardians of the child/adolescent signed a Consent Statement.

Prospective observational cohort study in five hospitals in the city of São Paulo (a city of 21 million inhabitants in Brazil). 916 interviews were conducted in the period from August $1^{\text {st }}$ to November $23^{\text {rd }}, 2012$, from noon to 8 PM (8 hours) every day of the week in five hospitals in the city, one in each region. The sample is representative of the general population in this age group.

A toolwas developed by Criança Segura -Safe Kids Brasil, Security Department of the
Brazilian Society of Pediatrics and PROTESTE (Brazilian Consumer Law Association) to collect data on parentand patient profile of unintentional injuryandtrauma severity.

Trauma site was observed being inside or outside home, and also in central or peripheral areas of the city. Those areas were both categorized by geographic location and also by economy.

Severity was considered with the following criteria: death, intubation, tomography, Revised Trauma Score (RTS) $<7$, Pediatric Trauma Score (PTS) $<8$, Glasgow $<14$, immediate surgery, admission to the ward or ICU, death.

\section{Statistical analysis}

Multivariate analysis of multiple binary logistic regression. P-value $<0.05$ was used as retention criterion variables in the model. Logodds in binary logistic regression analysis was assessed with SmoothedScatter Plots method and fractional polynomials. The presence of multicollinearity was assessed in covariates that presented $p<0.10$ in the univariate regression analysis (varianceinflation fator-VIF).

VIF values> 2.5 serve as considerable multicollinearity indicators were analysed with Hosmer-Lemeshow test and the area under the ROC curves (AUCs) respectively.

Proportions and means were compared between 2 seconds exact test groups of Fisher and Student's t test respectively.

The SAS version 9.3 software was used for statistical analysis of data.

\section{Results}

Trauma profile did not vary among the five regions of the city, although $53.8 \%$ of accidents occurred in the peripheral part of the city. Suffocation occurred in babies aged less than one year; burns, poisoning and accidents with foreign bodies occurred from 1 to 4 years 
of age; accidents with animals, pedestrian and bicycle accidents were frequent in children aged from 5 to 9 years and sport accidents occurred in children from 10 to 14 years of age. Falls were the most common trauma mechanism in all ages studied. Table 1 shows the types of accidents and the respective incidence.

Table 1 - Accident characterization.

\begin{tabular}{lll}
\hline Types & N & \% \\
\hline Falls & 443 & 48.4 \\
Burn & 15 & 1.6 \\
Suffocation & 6 & 0.7 \\
Strangulation & 2 & 0.2 \\
Animals & 14 & 1.5 \\
Penetrating injury & 40 & 4.4 \\
Bicycle & 46 & 5.0 \\
Sports & 87 & 9.5 \\
Choking/foreign body & 70 & 7.6 \\
Traffic (running over/ & & \\
occupant) & 54 & 5.9 \\
Poisoning/Intoxication & 23 & 2.5 \\
Other accidents & 116 & 12.7 \\
TOTAL & 916 & 100 \\
\hline
\end{tabular}

The caregiver/parent's profile shows that $83.5 \%$ of the parents were female with a mean age of 33.4 years; DP 9.744 (32.75; 34.02).

The children/adolescents traumatized profile shows that $61.5 \%$ were male and 38.5 female.

Approximately two-thirds (67\%) of traumatized children/adolescents were male aged between one and nine years when the accident occured (< one year: 7\%; $1-4$ years: 36 , 5-9 years: 31\%; 10 to 14 years: $26 \%$ ); average 6.5 years and median of 6 . Falls were responsible for $48,4 \%$ of cases.

$94 \%$ of children / adolescents traumatized live with their mothers; about $60 \%$ of parents and/ or siblings. Average of 2.5 residents per household.18\% were alone at the time of the accident.
Most of the children / adolescents who suffered unintentional injuries belong to families living with an average monthly income equivalent to almost three times the minimum wage - minimum wage $=\mathrm{R} \$ 622.00$ (as of January 2012), with an average of $R \$$ $1,751.00 .47 .9 \%$ live in the East part of the city.

Concerning falls, 176 (39.7\%) were from own height, 72 (16.3\%) from ladders, $4(0.9 \%)$ walkers, 18 (4.1\%) sofas, 2 feeding chairs $(0.5 \%), 32$ in playgrounds $(7.2 \%), 45$ from cribs (10.2\%), 6 from beds $(1.4 \%), 32$ from baby changers (7.2\%), 10 from windows and balconies (2.3\%), 10 from chairs $(2.3 \%), 6$ from slabs (1.4\%), 7 from walls (1.6\%), 3 from hammocks $(0.7 \%), 4$ from lap $(0.9 \%), 3$ from child seats $(0.7 \%)$ and 13 from other causes (2.9\%). Burns occurred due to scalding in 9 patients, stove in 2, 1 in hot water in the bath, 1 with iron, 1 with hot pan and 1 with silver nitrate. Drug poisonings occurred in 6 patients (5 with pills) and 13 with cleaning products. There was reference of 6 reutilized packages, similar to those of soft drinks, used to store cleaning products.

It was reported 14 cases of animal accidents, 13 with dogs and 1 with cat.

Pedestrian accidents $(n=48)$ occurred by car $(72.5 \%)$, bus $(2.1 \%)$, motorcycle $(10.4 \%)$, bicycle (2.1\%) and other (12.5\%). 39 (81.3\%) occurred on the street, not in the home-school path, where 5 (10.4\%) occurred and 4 (8.3\%) in the school-home path. Previous accidents was present in $26.5 \%$ of the children. Of those, $11 \%$ had $1,6 \%$ had $2,4 \%$ had 3 and $4 \%$ had 4 previous accidents; average of 2.3 accidents per child. $42 \%$ of unintentional injuries occured at home $(30 \%$ at home and $12 \%$ in the outer area), while $58 \%$ happen elsewhere: $21 \%$ in school; $18 \%$ on the street near home and $2 \%$ outside the neighborhood and $6 \%$ in recreation areas.

Severity was evaluated with the following criteria: 
Mortality: no deaths occurred during the observation period.

Glasgow Coma Scale (GCS): GCS ranged from 6 to 15, average of 14.91, SD 0.735 (14.86; 14.96). There was no information in 11 patients (1.2\%). According to ATLS grading of GCS severity the patients were as follows:

- Severe (3-8): 5 patients (0.5\%)

- Moderate (9-13): 8 patients $(0.8 \%)$

- Mild (14-15): 883 patients (96.4\%)

Intubation: 21 patients were intubated (2.4\%), there's no information in 31 patients (3.4\%)

Revised Trauma Score (RTS): calculated in only $50.4 \%$ of cases; ranged from 3.57 to 7.84; with an average of 7.484 , SD 0.584 (7.431; 7.537). RTS >7 in 415 patients $(89.8 \%)$ and $\mathrm{RTS}<7$ in 47 patients (10.2\%).

Exams: $69 \%$ of patients underwent additional examinations (average 1.3 tests per patient). Seven out of 10 cases had some kind of examination, especially $\mathrm{X}$ - rays and $\mathrm{CT}$, which was performed in 131 cases $(20,7 \%)$.

Pediatric Trauma Score: calculated in only $57.6 \%$ of cases; ranged from 3 to 12 , with an average of 10.62 , SD 1,489 (10.5; 10.75). PTS>8: 509 patients (96.4\%); PTS> 8-19 patients (3.6\%).
Patient destination after initial care is shown in Table 2.

Table 2 - Patient destination after the initial care.

\begin{tabular}{lll}
\hline Destination & N & \% \\
\hline Observation in Emergence Department & 140 & 15.3 \\
Observation in Ward & 52 & 5.7 \\
Immediate surgery & 14 & 1.5 \\
ICU & 11 & 1.2 \\
Discharged home & 576 & 62.9 \\
Discharge and outpatient treatment & 116 & 12.7 \\
Other & 7 & 0.8 \\
\hline
\end{tabular}

It was observed 224 severity criteria in 77 patients ( $8.5 \%$ of the sample); 8 patients were suspicious of child abuse.

In the univariate analysis, severity was related to child's age $(p<0.001)$, parent age ( $p<0.001)$, falls $(p<0.001)$, sports $(p<0.001)$, foreign body $(p=0.043)$, pedestrian $(p=0.006$ ), penetrating injury $(p=0.018)$, poisoning $(p=0.005)$, cared by male $(p<0.001)$, child's education $(p<0.001)$, housing in central regions $(p=0.003)$ (Table 3$)$.

Table 3 - Binary logistic regression for severity - Univariate analysis.

\begin{tabular}{lllllll} 
Covariates & $\begin{array}{l}\text { Yes } \\
(\mathrm{N}=224)\end{array}$ & $\begin{array}{l}\text { Total } \\
(\mathrm{N}=915)\end{array}$ & OR & $\begin{array}{l}\text { Inf } \\
\mathbf{9 5 \% C l}\end{array}$ & sup95\%Cl & $\mathbf{p}$ \\
\hline $\begin{array}{l}\text { Patient's Age } \\
\text { Parent Age }\end{array}$ & & $\mathrm{N}=852$ & 0.922 & 0.883 & 0.962 & $<.001$ \\
$\begin{array}{l}\text { FALLS } \\
\text { No }\end{array}$ & $\mathrm{N}=915$ & 0.971 & 0.955 & 0.988 & $<.001$ \\
Yes & $90(40.2 \%)$ & $472(51.6 \%)$ & $1.0($ Ref.) & & & \\
Total & $134(59.8 \%)$ & $443(48.4 \%)$ & 1.84 & 1.355 & 2.5 & $<.001$ \\
SPORTS & 224 & 915 & & & & \\
No & & & & & & \\
Yes & $220(98.2 \%)$ & $828(90.5 \%)$ & 1.0 (Ref.) & & & \\
\hline
\end{tabular}




\begin{tabular}{|c|c|c|c|c|c|c|}
\hline Total & 224 & 915 & & & & \\
\hline \multicolumn{7}{|l|}{ FOREIGN BODY } \\
\hline No & 215 (96.0\%) & 850 (92.9\%) & 1.0(Ref.) & & & \\
\hline Yes & $9(4.0 \%)$ & $65(7.1 \%)$ & 0.475 & 0.231 & 0.976 & 0.043 \\
\hline Total & 224 & 915 & & & & \\
\hline \multicolumn{7}{|l|}{ RUNNING OVER } \\
\hline No & 204 (91.1\%) & 867 (94.8\%) & 1.0(Ref.) & & & \\
\hline Yes & $20(8.9 \%)$ & $48(5.2 \%)$ & 2.321 & 1.281 & 4.208 & 0.006 \\
\hline Total & 224 & 915 & & & & \\
\hline \multicolumn{7}{|l|}{ PENETRATING WOUND } \\
\hline No & $221(98.7 \%)$ & 875 (95.6\%) & 1.0(Ref.) & & & \\
\hline Yes & $3(1.3 \%)$ & $40(4.4 \%)$ & 0.24 & 0.073 & 0.786 & 0.018 \\
\hline Total & 224 & 915 & & & & \\
\hline \multicolumn{7}{|l|}{ POISONING } \\
\hline No & $213(95.1 \%)$ & 894 (97.7\%) & 1.0(Ref.) & & & \\
\hline Yes & $11(4.9 \%)$ & $21(2.3 \%)$ & 3.517 & 1.473 & 8.395 & 0.005 \\
\hline Total & 224 & 915 & & & & \\
\hline \multicolumn{7}{|l|}{ PARENT AGE } \\
\hline$<18$ a 25 anos & $61(27.2 \%)$ & 189 (20.7\%) & 2.587 & 1.355 & 4.938 & 0.004 \\
\hline 26 a 35 anos & $100(44.6 \%)$ & 403 (44.0\%) & 1.792 & 0.97 & 3.308 & 0.062 \\
\hline 36 a 45 anos & 49 (21.9\%) & $233(25.5 \%)$ & 1.446 & 0.754 & 2.773 & 0.267 \\
\hline$>=46$ & $14(6.3 \%)$ & $90(9.8 \%)$ & 1.0(Ref.) & & & \\
\hline Total & 224 & 915 & & & & \\
\hline \multicolumn{7}{|l|}{ CAREGIVER / PARENT GENDER } \\
\hline Male & $20(8.9 \%)$ & $151(16.5 \%)$ & 0.419 & 0.255 & 0.689 & $<.001$ \\
\hline Female & $204(91.1 \%)$ & $764(83.5 \%)$ & 1.0(Ref.) & & & \\
\hline Total & 224 & 915 & & & & \\
\hline \multicolumn{7}{|l|}{ CHILD/ADOLESCENT SCHOOLING } \\
\hline Prekindergarten/Kindergarten & $55(24.8 \%)$ & $242(26.5 \%)$ & 0.496 & 0.333 & 0.736 & $<.001$ \\
\hline 1st to 9 th years & $75(33.8 \%)$ & $424(46.4 \%)$ & 0.362 & 0.253 & 0.518 & $<.001$ \\
\hline Out ofschool & $92(41.4 \%)$ & $247(27.1 \%)$ & 1.0(Ref.) & & & \\
\hline Total & 222 & 913 & & & & \\
\hline \multicolumn{7}{|l|}{ HOUSING } \\
\hline Central & $54(24.1 \%)$ & $382(41.8 \%)$ & 0.329 & 0.159 & 0.68 & 0.003 \\
\hline Peripheral & $157(70.1 \%)$ & $493(53.9 \%)$ & 0.935 & 0.468 & 1.867 & 0.848 \\
\hline Total & 224 & 914 & & & & \\
\hline
\end{tabular}


In the multivariate analysis, the fact that the child has had a previuos accident enhances 3.6 times the chance of having a traffic accident $(p<0.003)$ and living in a peripheric area enhances 2.7 times the possibility of having a fall $(p<0.003)$.
As for severity, the multivariate analysis showed relation with falls $(p=0.001)$; sports $(p=0.045)$; pedestrian $(p=0.006)$; child education $(p=0.015)$ and cared by male ( $p=0.007)$ (Table 4).

Table 4 - Binary logistic regression for severity - Multivariate analysis.

\begin{tabular}{|c|c|c|c|c|c|}
\hline Covariate & & $\begin{array}{l}\text { Odds } \\
\text { Ratio }\end{array}$ & $\begin{array}{l}95 \% \mathrm{Cl} \\
\text { Low }\end{array}$ & $95 \% \mathrm{Cl}$ Up & $\mathbf{p}$ \\
\hline \multirow{2}{*}{ FALLS } & No & 1.0(ref.) & & & \\
\hline & Yes & 1.899 & 1.286 & 2.806 & 0.001 \\
\hline \multirow{2}{*}{ SPORTS } & No & 1.0(ref.) & & & \\
\hline & Yes & 0.285 & 0.083 & 0.974 & 0.045 \\
\hline \multirow{2}{*}{ RUNNING OVER } & No & 1.0(ref.) & & & \\
\hline & Yes & 2.811 & 1.342 & 5.889 & 0.006 \\
\hline \multirow{3}{*}{$\begin{array}{l}\text { CHILD/ADOLESCENT } \\
\text { SCHOOLING }\end{array}$} & Pre-kindergarten/Kindergarten & 0.652 & 0.416 & 1.02 & 0.682 \\
\hline & $1^{\text {st }}$ to $9^{\text {th }}$ years & 0.501 & 0.323 & 0.776 & 0.015 \\
\hline & Out of school & 1.0(ref.) & & & \\
\hline \multirow{2}{*}{$\begin{array}{l}\text { CAREGIVER/PARENT'S } \\
\text { GENDER }\end{array}$} & Male & 0.443 & 0.244 & 0.804 & 0.007 \\
\hline & Female & 1.0(ref.) & & & \\
\hline
\end{tabular}

\section{- Discussion}

This study design is unique in Brazil, designed by three institutions with credibility, in order to determine the severity of trauma and to test a tool to develop a pediatric trauma database that can guide prevention and prehospital and hospital care of pediatric trauma patients. Society must know about severity in non intentional pediatric trauma, in order to enhance the prevention awareness.

According to the World Health Organization (WHO) ${ }^{1}$, every day 2000 families in the world are shattered by an unintentional accident or injury that could have been avoided. Over $95 \%$ of deaths from unintentional injuries occur in underdeveloped or developing countries. From what is about prevention, little is reverted in action. It is expected that globalization will increase traffic acidents in $67 \%$ until $2020^{\circ}$.

In Brazil, the main causes of deaths in children 0-14 years are traffic accidents and drownings. In the present study falls were the most frequent cause of hospitalization, in agreement with official hospitalization data.

In the present study, $61.5 \%$ of patients were male, with mean age of 6.5 years, mostly between 1 and 9 years of age. In children under 1 age, suffocation is the most important cause of death due to external causes. The most common accident in children 4 years of age 
were falls, foreign body, poisoning, burning, choking and larger suffocation. Children from 5 to 9 years had a higher incidence of accidents with traffic (pedestrians), animals, bruises, sprains, penetrating injuries and cuts; bicycle accidents (from 5 to 14 years) and sports (1014 years). Boys are more frequently involved in all types of accidents, except for burns, which tend to be more common in girls aged 1 to 4 years old ${ }^{9}$; a trend that can also be observed in this study: of the 15 cases, nine occurred in children aged 1 to 4 years, six of these were girls.

Falls were very common in smaller children (own height, ladder, beds, playgrounds, child seats and other devices ${ }^{10}$ ).

The incidence of poisoning increases around 9 months and continues to increase up to 21 to 23 months and then decreases. Cleaning products were responsible for most cases of poisoning: bleach, caustic soda, remover, soap, bar soap were the agents identified in the sample. Many of these products were packed in reused packages, which show the habit of families to keep these products usually under the kitchen sink, and to pack the products in PET bottles, making kids think it's a soft drink and end up ingesting the substance.

In cases of drug poisoning, many of them are colorful or parents say that it tastes nice, making them attractive to children.

In the present study there was an association between poisoning and severity in univariate analysis. There were burns on $1.6 \%$ of the sample caused by scalding, stove, hot water in the bath, iron, silver nitrate, and hot pan. All these cases would be easily prevented.

In this series there were suffocation/ choking, associated with severity in the univariate analysis. The high incidence of accidents with fingers and hands in doors, gates and drawers observed in the present study enhances the need for adequate safety devices.
Regarding accidents with animals, some can be severe, being a frequent cause of hospitalization, but are rarely fatal. Children are particularly susceptible to dog attacks because of its size and the factthe face that is close to the animal. So, head and neck injuries are common in young children and its frequency decreases with increasing age. These accidents frequently withdrawal children from school ${ }^{11}$.

Children, parents and dog owners should be trained to avoid dog attacks. The child should not be blamed for the attack, but one should teach them types of behavior to avoid attacks. In this series, there were 14 cases of accidents with animals: 13 with dogs ( 5 were their own dogs, two were from the street and 7 were friends or relatives dogs), and one with cat.

Pedestrian accidents are the main categories involving children in traffic accidents $^{12}$ and in Brazil they are the leading cause of death in traffic in the age group 1-14 years old. It is also estimated that with the motorization of China and India the numbers relating to traffic accidents increase exponentially.

Children are more susceptible because they are less visible than adults and the body topography hit by the motor vehicle can vary according to age and height of the child.Energy transferred is "focused" in a smaller mass that justifies the high mortality rate in children. In this series there were 48 traffic accidents: 35 were car occupants and 13 pedestrians. Importantly, children play on the street in underdeveloped and developing countries, which could explain the frequency pedestrians on the street described in this study. Studies show that improvements on the home-school / school-home path can have an impact in reducing pedestrian accidents, however, in the present study it was observed that $81.3 \%$ of pedestrians occurred in the street outside home-school path, and $26 \%$ of children in 
this sample were out of school. Two of the occupants were not wearing safety devices and one was at the front seat, although that is prohibited by law in Brazil.

A study conducted by the NGO Criança Segura- Safe Kids Brazil ${ }^{13}$ before the children safe transportation law showed that $40 \%$ of children were transported in cars and only $32 \%$ had a proper safety device. Another study ${ }^{14}$, two years after the law, evaluated the habits of people carrying children in Brazil and still did not use safety devices due child's physical size (32\%), no fiscalization (23\%), and device cost (6\%).

Sport activities injuries were frequent in this series, as in literature ${ }^{15}$. An association between sports and child age, parent age, parent sex, child sex, child's schooling, and history of previous accidents in univariate analysis; and the child's age, child sex and male parent in the multivariate analysis. It was also observed association with severity, both in the univariate analysis, and in the multivariate analysis.There were no safety devices use for cyclists and sports practitioners in this series, due to equipment cost and lack of prevention culture in the country.

Falls were the main trauma mechanism described in the present study, and are responsible for 47.000 deaths worldwide and in Brazil annually ${ }^{5}$. Several of them may be due to abuse ${ }^{16}$. They were associated with child age, parent age - less than 18 to 25 years, parent sex, child's education, and peripheral region. Multivariate analysis confirmed the fall association with the child's age and housing at the peripheral regions, the later fator enhances in 2.7 times the chance of having a fall.

The impact depends on the height of fall, which can happen in a playground toy or from windows or roofs ${ }^{17-23}$. In the present series high height falls were associated with severity.

In this study, $59.8 \%$ of respondents thought that the accident could have been prevented, however, only $5 \%$ cited safety devices as a prevention method.

The risk increases substantially when the family consists only with a parent when there are many brothers or when the controller is addicted or unemployed, compromising their ability to adequately supervise the child. This may explain indirectly the association of male parent with some injuries and severity in the series. In larger families there is a practice of child care by older siblings, which is inappropriate. In this series, when accompanied at the time of the accident, the children were with other children (31\%) or with his mother, and $18.9 \%$ were alone. In this study, a relationship was found between the male adult and severity in the univariate analysis, and multivariate analysis; falls in the univariate analysis and sports accidents and bicycles in the univariate analysis and multivariate analysis. The use of drugs or alcohol was not evaluated in this study. Regarding the type of accident, in families with income up to 2 minimum wages were associated with poisoning, burns, choking, accident with animal, contusion, and sprain.

There are few studies that relate accidents to the socioeconomic condition in the literature ${ }^{24}$ and they are even rarer in developing countries ${ }^{25}$, which reinforces the value of the contribution of the present study.

In this study, the fact that the accident recurrence rate was $26.5 \%$; and $11 \%$ had one previous accident, $6 \%$ had two, $4 \%$ had three and $4 \%$ had four or more previous history accidents may reflect the lack of quality supervision of children.

The fact that only $50.4 \%$ of patients had RTS and $57.6 \%$ had PTS shows that healthcare professional have difficulty in obtaining vital signs in children and are not used to trauma scores. ${ }^{7}$ Also physiologic scores, such as RTS have limitations because normal heart and respiratory rates in children are much higher 
than in adults ${ }^{26}$.

In addition to the RTS and the PTS, we considered severity factors the following variables: mortality (which did not occur until the end ofinterviews in this series), intubation, use of tomography, Glasgow less than14, need for immediate surgery, hospitalization in a ward or ICU. $8.5 \%$ of the cases had severity criteria ( 224 criteria in 77 patients) and 8 cases of suspected abuse. Severity was associated with the child's age, parent age between 18 and 25 years, falls, sport accident, foreign body, pedestrian, penetrating injury, poisoning, male parent, child's education, and housing in central regions in univariate analysis. In the multivariate analysis, remained: falls, sports events, pedestrians, schooling from first to ninth grade, and male parent.

Most injured children / teenagers live, in peripheral regions in São Paulo city, are males with average age of 6.4 years. Most accidents occured inside the house, but accidents in school / daycare and on the street are also frequent. Every three in ten injured children report previous accidents. The profile of those responsible is female, aged between 26 and 44 years, low average education level and family income of up to three minimum wages. Severity criteria in $8.5 \%$ of the sample. $59.8 \%$ of respondents think the accidents could be prevented. Simple preventive measures could have prevented most of the accidents. It was also observed low compliance regarding the use of safety devices. These findings reinforce the need for awareness campaigns on prevention of accidents.

Unlike what happened in the world in the last 40 years in relation to the organization of care for adult polytrauma, with unquestionable impact on reducing morbidity and mortality, the same was not true for the traumatized child.

Much can be done to reduce morbidity and mortality of pediatric trauma, from prevention, through antenatal, prehospital and intra hospital and also in rehabilitation care ${ }^{29-29}$.

The importance of a reliable database and international cooperation are the pillars for successful prevention programs. All countries should urgently investigate the problem of pediatric trauma and develop an action plan coordinated with different sectors of society.

It is essential that each site analyses its profile because the developed country experiences may not be transferable to other contexts, which reinforces the importance of this study.

The world has witnessed the "child survival revolution" in 30 years, withdecline in infant mortality. Now it is necessary to treat the damage caused bytrauma to the child and society. Every dead or sequeled child costs too much for the economy of a country, besides the incalculable emotional damage. Preventive measures minimize costs for the system health, and, most importantly, protects children.

\section{Conclusions}

Pediatric trauma severity was associated to falls, sports, traffic, child education, and cared by male. Simple preventive measures could have prevented most of the accidents. The tested tool for details was successful and can be used throughout the country.

\section{References}

1. Peden $M$, Oyegbite $K$, Ozanne-Smith J, Hyder AA, Branche C, Rahman AKMF, Rivara F, Bartolomeos K, editors. World report on child injury prevention. Geneva: World Health Organization; 2008. WHO Guidelines Approved by the Guidelines Review Committee. PMID: 26269872.

2. Nance ML, Carr BG, Branas CC. Access to pediatric trauma care in the United States. Arch Pediatr Adolesc Med. 2009;163(6):5128. PMID: 19487606.

3. Stamell EF, Foltin GL, Nadler EP. Lessons 
learned for pediatric disaster preparedness from September 11. 2001. J Trauma. 2009;67:S84-7. PMID: 19667859.

4. Abib SCV, Schettini ST, Figueiredo LFP. Prehospital pediatric trauma classification (PHPTC) as a tool for optimizing trauma care resources in the city of São Paulo, Brazil. Acta Cir Bras. 2006;21(1):7-11. doi: S010286502006000100003.

5. DATASUS. Data of the Unified Health System. Ministry of Health, Department of SUS. Available in http://w3.datasus.gov.br/ datasus/datasus.php.

6. ONG Criança Segura. Disponível em www. criancasegura.org.br.

7. Tallo FS, Abib SCV, Baitello AL, Lopes RD. An evaluation of the professional, social and demographic profile and quality of life of physicians working at the Prehospital Emergency Medical System (SAMU) in Brazil. Clinics. 2014;69(9):601-7. PMID: 25318091.

8. Peden $M$, Scurfield $R$, Sleet $D$, Mohan $D$, Hyder AA, Jarawan E, Mathers C. World report on road traffic injury prevention. Geneva: World Health

9. Morrongiello BA, Rennie H. Why do boys engage in more risk taking than girls? J Pediatr Psychol. 1998;23:33-43. PMID: 9564127.

10.Beaudin M, Maugans T, St-Vil D, Falcone RA. Inappropriate use of infant seating devices increases risks of injury. J Pediatr Surg. 2013;48:1071-6. PMID: 23701785.

11.Schalamon J, Ainoedhofer $H$, Singer G, Petnehazy T, Mayr J, Kiss K, Hollwarth ME. Analysis of dog bites in children who are younger than 17 years. Pediatrics. 2006;117(3):e374-9. PMID: 16510617.

12.Killingsworth JB, Tilford JM, Parker JG, Graham JJ, Dick RM, Aitken ME. National hospitalization impact of pediatric allterrain vehicle injuries. Pediatrics. 2005;115(3):e316-21. PMID: 15741358.

13.Abib, SCV, Françoia A, O’Reilly L. ONG Criança Segura - Safe Kids Brasil, 2010. Accidents with children: perception and behavior of Brazilian mothers. Available in www.criançasegura.org.br.

14.Abib SCV, Françóia AM, Ricci F, Cezillo MVB, Müller BR. Children safety devices in Brazil. Why do people don't use them after the law? J Transportation Technol. 2014;4:20515.
15.Janssen I, Dostaler S, Boyce WF, Pickett W. Influence of multiple risk behaviors on physical activity. Related injuries in adolescents. Pediatrics. 2007;119(3):e67280. PMID: 17332187.

16. Overpeck MD, McLoughlin E. Did that injury happen on purpose? Does intent really matter? Inj Prev. 1999;5:11-2. PMID: 1730446.

17.Pickett W, Streight S, Simpson K, Brison RJ. Injuries experienced by infant children: a population-based epidemiological analysis. Pediatrics. 2003;111:e365-70. PMID: 12671153.

18.Potoka DA, Schall LC, Ford HR. Improved functional outcome for severely injured children treated at pediatric trauma centers. J Trauma. 2001;51:824-34. PMID: 11706326.

19. Committee on Injury and Poison Prevention. American Academy of Paediatrics. Falls from heights: windows, roofs and balconies. Pediatrics. 2001; 107(5):1188-91. PMID: 11331708.

20.Norton C, Nixon J, Sibert JR. Playground injuries to children. Arch Dis Child. 2004;89:103-8. PMID: 1719797.

21.Bertocci GE, Pierce MC, Deemer E, Aguel $F$, Janosky JE, Vogeley E. Influence of fall height and impact surface on biomechanics of feet-first free falls in children. Injury. 2004;35:417-24. PMID: 15037378.

22.Petridou E, Sibert J, Dedoukou X, Skalkidis I, Trichopoulos D. Injuries in public and private playgrounds: the relative contribution of structural, equipment and human factors. Acta Paediatr. 2002;91(6):691-7. PMID: 12162604.

23. Allen EM, Hill AL, Tranter E, Sheehan KM. Playground safety and quality in Chicago. Pediatrics. 2013;131(2):233-41. PMID: 23339221.

24. Reading R. Area socioeconomic status and childhood injury morbidity in New South Wales, Australia. Child Care Health Dev. 2008;34:136-7. PMID: 2610604.

25. Butchart A, Kruger J, Lekoba R. Perceptions of injury causes and solutions in a Johannesburg township: implications for prevention. Soc Sci Med. 2000;50(3):33144. PMID: 10626759.

26.Abib SCV, Schettini ST, Figueiredo LFP. Prehospital pediatric trauma classification (PHPTC) as a tool for optimizing trauma care 
resources in the city of São Paulo, Brazil. Acta Cir. Bras. 2006;21(1):7-11. doi: S010286502006000100003.

27.Ramos TP, Abib SCV, Almeida Lima DP. Profile of the politraumatized patient. XVII Scientific Initiating Congress. Federal University of São Paulo; 2009.

28.Sympson AJ, Rivara FP, Pham TN. Quality care in pediatric trauma. Int J Crit IIIn Inj Sci. 2012;2(3):149-55. PMID: 3500007.

29.Myers SR, Branas CC, Kallan MJ, Wiebe DJ, Nance ML, and Carr GC. The use of home location to proxy injury location and implications for regionalized trauma system planning. J Trauma. 2011;71:1428-34. PMID: 21610527.

\section{- Acknowledgements}

This study was conducted by Safe Kids Brazil with the Brazilian Society of Pediatrics and PROTESTE and special contribuition of the following institutions: Hospital Estadual de Sapopemba, Hospital Santa Marcelina, Hospital Dr. Fernando Mauro Pires da Rocha, Santa Casa de Misericórdia de São Paulo, Hospital Municipal Vereador José Storopolli, DATAFOLHA and IEP HCor.

\section{Correspondence:}

Simone de Campos Vieira Abib

Departamento de Cirurgia, UNIFESP

Rua Coronel Lisboa, 687

04020-041 São Paulo - SP Brasil

simoneabib@uol.com.br

Received: Mar 02, 2017

Review: May 08, 2017

Accepted: June 05, 2017
Conflict of interest: none

Financial source: none

${ }^{1}$ Research performed at Department of Sur-
gery, Operative Technique and Experimental
Surgery, Universidade Federal de São Paulo
(UNIFESP), and Organização Não Governamen-
tal (ONG) Criança Segura, Sao Paulo - SP, Brazil. 